\title{
ÖRGÜTSEL ÇATIŞMA VE YÖNETIMI: Spor Eğitimi Veren Yükseköğretim Kurumlarında Bir Uygulama
}

\author{
Nevzat MIRZEOĞLU1
}

\section{ÖZET}

Çatışma, sosyal yaşamın normal bir boyutu olduğu gibi, örgütsel yaşamında bir gerçeğidir. Çatışma kaçınılmaz olduğuna göre, çağdaş örgütlerin ve yöneticilerin örgütsel amaçları gerçekleştirmek için, çatışmadan yararlanmayı öğrenmeleri önemli görevleri arasındadır. Çatışma yönetimi, birey ve örgüt gelişimi için pozitif sonuçlara ulaşmayı ve negatif sonuçları engellemeyi amaçlar. Bu araştırmanın amacı; spor eğitimi veren yüksek öğretim kurumlarında görev yapan yöneticilerin, çalışanlar arasında çatışma çıkması durumunda kullandıkları çatışma yönetim sitillerini belirlemek ve yönetici-öğretim elemanı görüşlerini karşılaştırmaktır.

Araştırma tarama modelindedir. Araştırma evreni olarak Türkiye'de spor eğitimi veren 9 üniversite, çalışma grubu olarak da bu üniversitelerin ilgili bölümlerinde görev yapan tüm yöneticiler ve gönüllü katılan öğretim elemanları seçilmiştir. Toplam 38 yönetici, 70 öğretim elemanı araştırmada yer almıştır. Veri toplama aracı olarak anket tekniği kullanılmış ve verilerin çözümlenmesinde frekans analizi, $\mathrm{t}$-test ve tek yönlü varyans analizi tekniklerinden yararlanılmıştır.

Araştırma bulgularına göre; spor eğitimi veren yükseköğretim kurumlarında yöneticilerin çatışma yönetiminde öncelik sırasına göre problem çözme, uzlaşma, ödün verme, kaçınma ve hükmetme sitillerini kullandıkları, "problem çözme" ve "uzlaşma" sitilleri hakkında öğretim elemanlarının görüşleri ile yönetici görüşleri arasında 0.05 düzeyinde anlamlı fark olduğu görülmüştür. Aynı sitiller açısından yönetici ve öğretim elemanlarının unvan durumlarına göre gruplar arasında 0.05 düzeyinde anlamlı fark bulunmuştur.

Sonuç olarak; spor eğitimi veren yükseköğretim kurumlarında görev yapan yöneticilerin çatışma durumunda genellikle problem çözme ve uzlaşma sitillerini kullandıkları, ayrıca unvan durumlarının çatışma yönetimi açısından önemli bir değişken olduğu ortaya çıkmıştır.

Anahtar Kelimeler: Çatışma, Örgütsel Çatışma, Çatışma Yönetimi

\section{ORGANIZATIONAL CONFLICT AND MANAGEMENT: A Study at The Schools of Physical Education and Sport}

\begin{abstract}
The reality of organizational life, conflict is a dimension of life. As the conflict is inevitable for most of the circumstances, modern organizations and administrators should find out how to get benefit of it as much as possible in order to proceed with the goals of the organizations. The aim of conflict management is to reach positive outcomes and to prevent the negative consequences for the necessary development of the organization.

The purpose of this study is to determinate the styles of conflict management and to compare administrators and lecturers' points of view. In this study, 38 administrators and 70 lecturers from 9 universities in Turkey working at the divisions of sport sciences were questioned. T-test and one way variant analysis were used $(p<0.05)$ for the statistical analysis of the data.

The results of the study have revealed that styles of problem solving, compromise, concession, avoid, and oppress were conducted by the administrators who have been working at a school of physical education and sport. There were significant differences between administrators and lecturers' points of view regarding the styles of problem solving and compromise. Nevertheless, there were also significant differences at the same styles, which is bound to the tittles of administrators and lecturers.
\end{abstract}

Key Words: Conflict, Organizational Coflict, Coflict Management

\footnotetext{
${ }^{1}$ Abant İzzet Baysal Üniversitesi Beden Eğitimi ve Spor Yüksekokulu
} 


\section{Giriş}

Örgütlerde etkinlik ve verimliliği etkileyen çok fazla değişken bulunmaktadır. Bunlardan bazıları, başta insan kaynağı olmak üzere örgütü oluşturan tüm kaynaklar, yönetim stratejileri, amaçlar, sosyal çevre, müşteri beklentileridir. Örgütsel çatışma ve yönetimi de bu değişkenler arasında yer almaktadır.

Çatışma, sosyal yaşamın normal bir boyutu olduğu gibi, örgütsel yaşamında bir gerçeğidir (1). Çatışma kaçınılmaz olduğuna göre, çağdaş örgütlerin ve yöneticilerin örgütsel amaçları gerçekleştirmek için, çatışmadan yararlanmayı öğrenmeleri önemli görevleri arasındadır (2). Çatışma yönetimi, birey ve örgüt gelişimi için pozitif sonuçlara ulaşmayı ve negatif sonuçları engellemeyi amaçlar.

Bumin (3) çatışmayı değişimin bütünleştirici bir niteliği olarak kabul ederken, Açıkalın (4) ise; gruplaşmaların ve çatışmaların olmadığı bir örgütü ölü olarak niteleyerek yaşayan, etkinliği olan örgütlerde grupların ve çatışmaların varlığını doğal kabul etmektedir. Diğer taraftan Sertkan (5) çatışmayı bir liderlik stratejisi olarak savlamış ve doğrulamıştır. Bu anlamda çatışma ne pozitif ne de negatiftir. Çatışma tehlikelerin belirtisi olabileceği gibi, yeni fırsatların habercisi de olabilir. Sonucun hangi yönde olacağı çatışmanın anlaşılması ve yönetilebilmesine bağlıdır (2). Çatışma kavramının negatif olarak görülmesi, anlamı hakkında yeterli bilgiye sahip olmamaktan ve çatışmaya sadece yıkıcı bir anlam yüklemekten kaynaklanmaktadır (6).

Yöneticiler, çoğu kez çatışmayla karşılaştıklarında bu yanılgıların etkisiyle çatışmayla başa çıkmada yetersiz kalırlar. Yapılması gereken, çatışmanın ne olduğunu anlamaya çalışmak ve çatışmayla ilgili ön yargılardan kurtulmaktır.

Okullarda çatışmanın kaynağını Korkmaz (7); iletişim problemleri, örgütsel yapı, kişilik ve insan faktörleri ile sınırlı kaynaklar olarak ifade etmektedir. Okullarda yöneticilerin sahip olduğu kültürel özellikler, inanç ve değerlerin de öğretmenlerin güdülenmelerini ve sınıf içindeki etkinliklerini olumsuz yönde etkilediği bilinmektedir. İyi bir çatışma yönetimi stratejisi ile, çatışmadan olumlu sonuçlar elde edilebilir. Örneğin çatışma, örgütte güven ve anlayışın hakim olduğu bir atmosfer oluşturmak için kullanılabilir (8). Farklı görüşler, bilgiler ve varsayımlar başarılı kararlar için bir zorunluluktur. Çatışmayı etkili bir biçimde yöneterek; amaçları ve uygulamaları yeniden gözden geçirmek, kaliteyi artırmak, maliyeti düşürmek, kurumsal işlevleri etkilileştirmek, takım çalışması ve beyin fırtınasının etkililiğini sağlamak mümkün olabilir $(9,10,11,12,13)$.

İyi yönetilen çatışmanın bireye ve örgüte sağlayacağı yararları Karip (2) şöyle sıralamıştır; daha iyi ilişkilerin oluşturulması, psikolojik olgunluk, bireyin kendisine saygısının geliştirilmesi, bireysel gelişim, etkililiğin ve verimliliğin geliştirilmesi, problemlerin farkına varmak ve problemleri tanımak, daha iyi çözümler oluşturmak, örgütsel değişimi sağlamak, monotonluğu azaltmak, ahenkli bir takım çalışması oluşturmak. Eğitim yöneticileri, eğitim örgütlerinde ortaya çıkan çatışmaları yok etmek, görmezlikten gelmek ve çatışmanın var olmadığını kabul etmek yerine, onu yapıcı ve yaratıcı bir hareketin kaynağı olarak görmeleri gerekir. Görüldüğü gibi çatışma ve onun yönetimi örgüt verimliliğini etkileyen önemli faktörlerden birisidir.

Çatışma yönetimi, uzlaşmazlığı belirli bir yönde sonuca yöneltebilmek için çatışmaya taraf olanların yada üçüncü bir tarafın bir dizi eylemde ve karşı eylemde bulunmasıdır (2). Burada atılan adımlar çatışmayı sona erdirebilir yada erdiremez. Elde edilecek sonuç pozitif, barışçıl ve uzlaşmacı olabileceği gibi karşı tarafa üstünlük kurmaya yönelik de olabilir (14). Çatışma yönetimini bir çok bilim adamı ele almış ve çeşitli kuramlar üretmişlerdir. Bunlardan bazıları; Thomas'ın "Çatışma Yönetimi Sitilleri Modeli”, Blake ve Mouton'un "Çatışma Yönetim Biçimleri Ölçeği” ve Rahim ve Bonoma'nın "Çatışma Yönetim Modeli" dir. Bu üç kuramın çatışma yönetim stratejilerinin ifadesinde bir takım farklar olmasına karşın, içerik olarak son derece fazla benzerlikler bulunmaktadır $(15,2)$. Çatışma yönetim sitillerine ilişkin yapılan araştırmalarda ortaya çıkan ortak bir yargıdan söz edilebilir; Bu yargı çatışma yönetiminde 5 ayrı sitilin kullanıldığı ve bunların "Problem Çözme, Hükmetme, Ödün Verme, Kaçınma ve Uzlaşma” olduğudur.

Türkiye'de spor eğitimi veren kurum sayısı çok hızlı bir artış göstermektedir. Ancak bu kurumlar nicel olarak artarken nitel olarak bir gelişimden söz etmek çok akılcı olmaz. Bir eğitim örgütünü oluşturan temel unsurların yanında nitelikli öğretim elemanı ve yönetici ihtiyacının karşılanması çok önemli bir sorundur. Etkili yöneticilik çok yönlülüğe, iyi bir liderliğe ve sağlam bir eğitim alt yapısına bağlıdır. Çatışma yönetimi de etkili yöneticilerin temel görevlerindendir. Bu nedenle; “Türkiye' de Spor Eğitimi veren kurumlarda görev yapan yöneticilerin öğretim elemanları ile aralarında çatışma çıkması durumunda hangi çatışma sitilini kullandıkları ve öğretim elemanlarının bu duruma bakış açılarını belirlemek bu araştırmanın amacını oluşturmaktadır.

\section{MATERYAL VE YÖNTEM}

Katılımcılar: Araştırma evreni Türkiye'de spor eğitimi veren yükseköğretim kurumları ve bu kurumlarda görev yapan öğretim elemanları ile yöneticilerdir. Çalışma grubu ise; tesadüfi örneklem metodu ile seçilen 9 üniversitenin spor eğitimi veren yüksek okul ve bölümlerinde görev yapan yöneticilerin tamamı ve aynı kurumlardan araştırmaya gönüllü katılan öğretim elemanlarından oluşmaktadır. Çalışma grubuna 70 öğretim elemanı, 38 yönetici dahil edilmiştir. Çalışma grubunun \%26.9 u kadın, \%73.1 i erkektir. 
Veri Toplama Araçları: Verilerin elde edilmesinde Ural (16) tarafından geliştirilen ve geçerlik ve güvenirlik çalışması yapılan "Örgütsel Çatışmayı Yönetme Anketi” kullanıımıştır. Anket çatışma yönetim sitillerine ilişkin 25 davranış biçiminden oluşmaktadır. Ankette 5 ayrı yönetim sitiline ait 5 er madde dağınık düzende yerleştirilmiştir. Her davranış biçiminin gösteriliş sıklığı; hiçbir zaman, ara sıra, genellikle ve her zaman seçenekleri ile derecelendirilmiş ve hiçbir zaman 1, ara sıra 2, genellikle 3 ve her zaman 4 olarak puanlanmıştır. Anketin güvenirliği Ural (16) tarafından 5 ayrı ilk öğretim okulundan 54 öğretmene 1 ay ara ile iki defa uygulanarak test edilmiştir. Bu denemeler sonucunda güvenirlik katsayısı a= .8148 olarak hesaplanmıştır. Anketin geçerliği uzman görüşlerinden yararlanarak test edilmiştir. Anketin alt boyutlarını oluşturan beş sitil şunlardır; Problem Çözme Sitili, Kaçınma Sitili, Uzlaşma Sitili, Hükmetme Sitili, Ödün Verme Sitili.

Verilerin Analizi: Verilerin analizi için t-test, Anova, frekans, yüzde ve aritmetik ortalama teknikleri kullanılmıştır.

Verilerin Toplanması: Veri toplamak amacı ile anket uygulaması araştırmacı tarafından çalışma grubu üzerinde gerçekleştirilmiştir. Araştırmacı tarafından belirlenen kurumdaki yönetici ve öğretim elemanlarına posta yolu ile gönderilen anket yine posta yolu ile toplanmıştır. Yöneticilere gönderilen 42 anketten 38 i, Öğretim elemanlarına gönderilen 80 anketten 70 i geriye dönmüş ve hepsi araştırmaya dahil edilmiştir.

\section{BULGULAR}

Tablo 1. Yöneticilerin Çatışma Yönetimine İlişkin Kullandıkları Sitiller ve Öğretim Elemanlarının Görüşlerinin Karşılaştırılması (t- test)

\begin{tabular}{|c|c|c|c|c|c|}
\hline Çatışma Yönetme Sitilleri & Çalışma Grubu & $\mathbf{N}$ & $\mathbf{x}$ & s.s & $\mathbf{t}$ \\
\hline \multirow[t]{2}{*}{ Problem Çözme } & Yönetici & 38 & 17.57 & 1.99 & \multirow{2}{*}{$4.817^{\star \star}$} \\
\hline & Öğr. Elemanı & 70 & 14.44 & 3.72 & \\
\hline \multirow[t]{2}{*}{ Hükmetme } & Yönetici & 38 & 10.71 & 2.54 & \multirow{2}{*}{$-2.098^{*}$} \\
\hline & Öğr. Elemanı & 70 & 11.88 & 2.89 & \\
\hline \multirow[t]{2}{*}{ Kaçınma } & Yönetici & 38 & 11.73 & 2.46 & \multirow{2}{*}{.831} \\
\hline & Öğr. Elemanı & 70 & 11.35 & 2.15 & \\
\hline \multirow[t]{2}{*}{ Uzlaşma } & Yönetici & 38 & 15.97 & 2.24 & \multirow{2}{*}{$3.820^{* \star}$} \\
\hline & Öğr. Elemanı & 70 & 14.00 & 2.71 & \\
\hline \multirow[t]{2}{*}{ Ödün Verme } & Yönetici & 38 & 12.34 & 2.36 & \multirow{2}{*}{1.483} \\
\hline & Öğr. Elemanı & 70 & 11.60 & 2.54 & \\
\hline
\end{tabular}

s.d $=106 \quad{ }^{*} P<0.05 \quad{ }^{* *} p<0.01$

Tablo 1 incelendiğinde; yöneticilerin çatışma yönetimi için "problem çözme" sitilini kullanmaları açısından yönetici ve öğretim elemanlarının görüşleri arasında anlamlı fark olduğu anlaşılmaktadır $(p<0.01)$. Aritmetik ortalamalara $(X=17.57 \pm 1.99, X=14.44 \pm 3.72)$ bakıldığında; yöneticilerin çatışma yönetimi konusunda "problem çözme" sitilini kullandıklarını belirtmelerine rağmen, öğretim elemanları bu konuda aynı fikirde olmadıklarını ifade etmektedirler.

Çatışmayı yönetme sitillerinden "hükmetme" sitiline ilişkin yönetici ve öğretim elemanlarının görüşleri arasında da anlamlı fark olduğu gözlenmiştir $(p<0.05)$. Bu konudaki farkın öğretim elemanlarının çatışma yönetimi konusunda yöneticilerinin "hükmetme" sitilini kullandıklarına ilişkin algılarının, yöneticilerin ifade ettiklerinden daha yüksek olmasından kaynaklandığı söylenebilir ( $x=10.71 \pm 2.54, x=11.88 \pm 2.89)$. Bir başka çatışma yönetim sitili olarak kabul edilen "kaçınma" sitili açısından tabloyu incelediğimizde; her iki grubun görüşleri arasında anlamlı bir fark olmadığı görülmektedir ( $p>0.05)$. Yöneticilerin çatışma yönetimi konusunda "kaçınma" sitilini kullandıklarına ilişkin elde ettikleri değerler ile öğretim elemanlarının bu konuda elde ettikleri değerler paralellik göstermektedir.

"Uzlaşma" sitili konusunda araştırmaya katılan yönetici ve öğretim elemanlarının görüşleri arasında anlamlı fark bulunmuştur $(p<0.01)$. Bu konuda çalışma grubunun değerleri $(X=15.97 \pm 2.24, X=14.00 \pm 2.71)$ karşılaştıııldığında, aradaki farkın yöneticilerin "uzlaşma" sitilini kullandıklarını ifade etmelerine rağmen, öğretim elemanlarının bu oranda bu görüşe katılmadıklarını ifade etmelerinden kaynaklandığı söylenebilir. Bir başka örgütsel çatışma yönetim sitili olan "ödün verme" sitili konusunda, yönetici ve öğretim elemanlarının değerleri arasında anlamlı fark yoktur ( $p>0.05)$. Bu konuda yöneticilerin "ödün verme" sitili konusundaki eğilimlerine, öğretim elemanları da katılmışlardır. Yöneticilerin kullanış sıklığına göre en çoktan aza doğru kullandıkları sitiller ise; problem çözme, uzlaşma, ödün verme, kaçınma ve uzlaşmadır. 
Tablo 2. Yöneticilerin Ünvanlara Göre Çatışma Yönetiminde Kullandıkları Sitiller ve Öğretim Elemanı Görüşlerinin Karşılaştırılması (Anova)

\begin{tabular}{|c|c|c|c|c|c|c|c|c|}
\hline \multirow[b]{2}{*}{ Çatışma Yönetim Yöntemi } & \multirow[b]{2}{*}{ Unvan } & \multicolumn{3}{|c|}{ Yönetici } & \multicolumn{3}{|c|}{ Öğr. El. } & \multirow{2}{*}{$\mathbf{F}$} \\
\hline & & $\mathbf{x}$ & s.s & $\mathbf{N}$ & $\mathbf{x}$ & s.s & $\mathbf{N}$ & \\
\hline \multirow[t]{2}{*}{ Problem Çözme } & Yard.öğr.Üy & 17.20 & 2.34 & 10 & 14.31 & 3.95 & 44 & \multirow{2}{*}{$7.734^{\star \star}$} \\
\hline & Öğr.üyesi & 17.71 & 1.88 & 28 & 14.65 & 3.36 & 26 & \\
\hline \multirow[t]{2}{*}{ Hükmetme } & Yard.öğr.Üy & 10.80 & 2.97 & 10 & 11.97 & 2.68 & 44 & \multirow{2}{*}{1.489} \\
\hline & Öğr.üyesi & 10.67 & 2.43 & 28 & 11.73 & 3.26 & 26 & \\
\hline \multirow[t]{2}{*}{ Kaçınma } & Yard.öğr.Üy & 11.30 & 2.31 & 10 & 11.84 & 2.17 & 44 & \multirow{2}{*}{2.279} \\
\hline & Öğr.üyesi & 11.89 & 2.54 & 28 & 10.53 & 1.88 & 26 & \\
\hline \multirow[t]{2}{*}{ Uzlaşma } & Yard.öğr.Üy & 16.60 & 1.95 & 10 & 13.93 & 2.71 & 44 & \multirow{2}{*}{$5.107^{* *}$} \\
\hline & Öğr.üyesi & 15.75 & 2.33 & 28 & 14.11 & 2.77 & 26 & \\
\hline \multirow[t]{2}{*}{ Ödün Verme } & Yard.öğr.Üy & 12.20 & 2.29 & 10 & 11.72 & 2.42 & 44 & \multirow{2}{*}{.839} \\
\hline & Öğr.üyesi & 12.39 & 2.42 & 28 & 11.38 & 2.77 & 26 & \\
\hline
\end{tabular}

s.d. $=3 \quad{ }^{*}=p<0.05 \quad{ }^{* *} p<0.01$

Tablo 2 ye göre, "problem çözme" sitili konusunda yöneticilerle öğretim elemanlarının görüşleri arasında anlamlı fark bulunmuştur $(p<0.01)$. Bu farklıığın öğretim üyesi statüsünde olan yöneticilerle her iki statüde olan öğretim elemanlarının görüşlerindeki farklılıktan kaynaklandığı Tukey testine göre ortaya çıkmıştır. Öğretim üyesi olan yöneticilerin "problem çözme" sitiline ilişkin değerlerine göre, öğretim elemanı olarak yönetilenlerin değerleri daha düşük çıkmıştır (X=17.71 $\pm 1.88, X=14.31 \pm 3.95-14.65 \pm 3.36)$.

"Hükmetme", "Kaçınma" ve "ödün verme" sitillerinde unvan grupları arasında anlamlı fark yoktur $(p>0.05)$. Bu sitiller konusunda yöneticilerle öğretim elemanları yaklaşık değerde görüş ifade etmişlerdir.

Çatışma yönetim sitillerinden "uzlaşma" sitili hakkında unvanlara göre, gruplar arasında anlamlı fark bulunmuştur $(p<0.01)$. Bu farklılığın hem öğretim üyesi yardımcısı hem de öğretim üyesi olan yöneticiler ile öğretim üyesi yardımcısı öğretim elemanlarının görüş farklılıklarından kaynaklandığı tukey testiyle ortaya çıkmıştır.

\section{TARTIŞMA VE SONUÇ}

Çalışmanın sonuçlarına göre; araştırmaya katılan yöneticiler "problem çözme" sitilini her zaman kullandıklarını ifade ederken, "uzlaşma" sitilini ara sıra, "hükmetme, ödün verme ve kaçınma" sitillerini nadiren kullandıklarını ifade etmişlerdir. Bu sonuçlar genel olarak bu konuda yapılan bir çok araştırma sonuçlarıyla benzerlik göstermektedir (17, 18, 19, 20, 21). Blake ve Mouton örgütlerde bireyler arasında daha etkili ve iyi ilişkiler kurulmasında problem çözme metoduna daha fazla önem verilmesinin faydalı olacağını belirtmişlerdir. Lavrence ve Larsch (22) yaptıkları araştırmada problem çözme yöntemini uygulayan iki örgütte, diğer dört örgüte göre performansı daha yüksek bulmuşlardır. Yöneticiler hakkında elde ettiğimiz bu sonuç, örgütleri için olumlu bir durum olarak değerlendirilebilir.

Problem çözme sitili konusunda araştırmaya katılan öğretim elemanları ise yöneticilerinin algılarının tersine bir algı durumu ortaya koymuşlardır. Yani, öğretim elemanları çatışmalı bir durum söz konusu olduğunda; yöneticilerinin "problem çözme" sitilini arada bir kullandıklarını algılamaktadırlar. Bu konuda yönetici ve öğretim elemanlarının görüşleri arasında anlamlı fark bulunmuştur $(p<0.05)$. Elde edilen bu sonuç Gümüşeli (20) nin yaptığı çalışmada elde ettiği sonuçlarla ters düşmektedir. Gümüşeli'nin çalışmasında çatışma yönetimi sitillerine ilişkin olarak öğretmen ve yönetici görüşleri arasında bir uyum söz konusudur. Bizim çalışmada elde ettiğimiz sonucun nedeni, üniversite örgüt yapısındaki çok farklı kariyer ve statü de öğretim elemanlarının bulunması olabilir. Orta öğretim örgüt yapısında ise daha homojen olan ve sadece öğretmen ve yönetici statüsünde olan bir görünüm bulunmaktadır. Bu nedenle yönetici ve öğretmen görüş ayrılığı bulunmayabilir.

Çatışma yönetim sitillerinden "hükmetme" ile ilgili yöneticilerin algısı; çatışma çıkması durumunda bu sitili nadiren kullandıkları şeklindedir. Bu sonuç diğer araştırma sonuçlarını da teyit eder niteliktedir $(17,18,19,20,21)$. Ancak bu sonuçla öğretim elemanlarının görüşleri çelişmektedir. Öğretim elemanları yöneticilerinin çatışmalı bir durumda daha fazla hükmetme sitiline başvurduklarını algılamaktadırlar. Bu konuda yönetici ve öğretim elemanlarının görüşleri arasında anlamlı fark bulunmuştur. Öğretim elemanlarının çatışma yönetiminde hükmetme sitilinin kullanılmaması yönünde bir beklenti içinde oldukları anlaşılmaktadır. Araştırmalarda hükmetme ve kaçınma sitilinin kullanıldığı örgütlerde var olan çatışmaların çözümü bir tarafa, bu sitillerin kullanılması yeni çatışmalara neden olmaktadır ve bu örgütlerde çok fazla çatışma yaşandığı ortaya çıkmaktadır (23). Yönetici algıları açısından bakıldığında bu araştırmada elde edilen sonuç olumlu bir durum olarak değerlendirilebilir. 
Çalışmada, "kaçınma" sitili açısından yönetici ve öğretim elemanlarının görüşlerinin gerçek durumu yansıttığı görülmektedir. Yöneticiler çatışmalı durumda nadiren "kaçınma" sitilini kullandıklarını ifade ederken, öğretim elemanları da bu görüşü teyit etmişlerdir. Bu sonuç Wanasiri'nin (24) sonuçlarını doğrulamaktadır. Bu durum da araştırmanın yapıldığı örgütler açısından bir avantaj olarak değerlendirilebilir.

Bir başka çatışma yönetim stratejisi olarak kabul edilen "uzlaşma" sitili konusunda araştırmaya katılanların görüşleri arasında anlamlı fark bulunmuştur $(p<0.05)$. Bu farklılığın nedeni yöneticiler genellikle uzlaşma sitilini kullandıklarını belirtirken, öğretim elemanları buna katılmamış ve yöneticilerinin çatışmalı durumda uzlaşma sitilini ara sıra kullandıklarını belirtmişlerdir. Litton (1989) yaptığı araştırmada yüksekokul müdürlerinin uzlaşma sitilini kullanma eğiliminde oldukları sonucuna varmıştır (19). Yine, Wanasiri' de (24) yüksek müdürlerinin çoğunlukla uzlaşma sitilini kullandıklarını ifade etmektedir. Litton ve Wanasiri'nin elde ettiği sonuçlar yöneticilerin uzlaşma sitilindeki görüşlerini desteklemektedir. Öğretim elemanlarının bu konuda farklı düşünüyor olmalarının temelinde unvan farklııkları olabilir.

"Ödün verme" sitili açısından yönetici ve öğretim elemanlarının görüşleri bir birini desteklemektedir. Yani, çatışmalı bir durumda yöneticiler ödün verme sitilini nadiren kullanmaktadır. Bu sonuç bir çok araştırma sonucuyla benzerlik göstermektedir $(24,23)$.

Genel olarak yöneticilerin çatışma yönetim sitillerini kullanış derecelerine göre bir sıralama yapıldığında; Problem Çözme, Uzlaşma, Ödün verme, Kaçınma ve Hükmetme şeklinde sıralandığını görmekteyiz. Ancak yöneticilerin bu görüşlerine karşın, öğretim elemanlarının görüşleri farklı bulunmuştur. Bu duruma, çatışmayı yaşayanlar ve yönetenler açısından bakıldığında farklılığın nedeni; yöneticilerin teorikte çatışma durumunda neler yapacaklarını bilmelerine ve daha rasyonel düşünmelerine karşın, gerçekte çatışma yaşanması durumunda bildiklerini uygulamaya yansıtamıyor olabilirler. Bu sonuç ise, etkili yönetim ile sıradan yönetim arasındaki farkı vurgulamaktadır. En uygun zaman ve durumda doğru kararlar vermek ve uygun stratejik davranışlar sergilemek etkili liderlik ve yönetimin bir göstergesidir. Diğer taraftan, yöneticinin aldığı kararlar her zaman, herkesi mutlu etmeyebilir. Ancak, etkili yöneticilik göstergelerinden biri de örgüt içi çatışmalara rasyonel çözümler getirebilmektir.

Araştırmaya katılanların unvan durumları açısından çatışma yönetim sitillerine ilişkin görüşleri değerlendirildiğinde; bu değişkenin çatışma yönetim stratejilerini kullanmayla ilişkili olduğu görülmektedir. Ünvanın, özellikle problem çözme ve uzlaşma sitili açısından önemli bir değişken olduğu anlaşılmıştır. Özellikle yönetici öğretim üyeleri ile öğretim elemanları arasında önemli derecede görüş ayrılığı bulunmaktadır. Bu sonucu üniversitedeki hiyerarşik örgüt yapısının önemli ölçüde etkilediği düşünülebilir. Literatürde bu anlamda bir çalışmaya rastlanmamıştır. Ancak, çatışma yönetiminde statünün önemli bir değişken olduğunu vurgulayan çalışmalar bulunmaktadır (3). Unvan değişkeninin hükmetme kaçınma ve ödün verme sitilleri açısından önemli olmadığı anlaşılmaktadır.

Sonuç olarak; Türkiye'de spor eğitimi veren yükseköğretim kurumlarında görev yapan yöneticiler kurumlarındaki çatışmaları yönetmede öncelik sırasına göre "problem çözme, uzlaşma, ödün verme, kaçınma ve hükmetme" sitillerini kullanmaktadırlar. Bu kurumlarda çalışan yönetici ve öğretim elemanlarının unvan durumlarıda çatışma yönetim stratejisini etkileyen önemli bir değişkendir. Özelikle bu değişkenler "problem çözme ve uzlaşma açısından daha önemlidir.

Araştırmalarda çatışma yönetiminde çok farklı stratejilerden söz edilmektedir. Bu stratejiler çatışmanın kaynağına, düzeyine ve çatışma yaşayan taraflara göre değişik şekillerde kullanılmaktadır. Her strateji ve sitil her çatışma durumu için uygun olmayabilir. Bu nedenle yöneticilerin yaşanan çatışma durumuna uygun bir strateji belirleyerek rasyonel bir yönetim sergilemesi esastır. Türkiye üniversitelerindeki hiyerarşik örgüt yapısı dikkate alındığında öğretim elemanlarının daha fazla kararlara katııma, daha esnek bir yönetim tarzı ve sorunların çözümünde işbirliği ve uzlaşmacı bir anlayış beklentisi içinde oldukları görülmüştür.

$\mathrm{Bu}$ araştırma spor eğitimi veren kurumlarda çatışma olduğu varsayımına dayalı olarak; çatışma yönetiminde kullanılan sitilleri tespit etmek amacıyla planlanmıştır. Bu örgütlerdeki çatışma kaynakları, türleri ve çatışma düzeylerini belirlemek için başka çalışmalar yapılmalıdır. Ayrıca, çatışma yönetimi ve performans, çatışma yönetimi ve iş doyumu ilişkisi gibi problemlerin incelenmesi örgütsel davranış ve verimlilik açısından önemli katkılar sağlayabilir.

\section{KAYNAKLAR}

1. Rahim, M. A. "Managing Conflict in Organizations, Praeger Publishers", New York, 1986.

2. Karip, E.,"Çatışma Yönetimi”, Pegem Yayıncılık, Ankara, 2000.

3. Bumin, B., "İşletmelerde Organizasyon Geliştirme ve Çatışma Yönetimi”, Bizim Büro Basım Evi, Ankara, 1990.

4. Açıkalın, A., “Teknik ve Toplumsal Yönleri İle Okul Yönetimi” Pegem Eğitim Merkezi Yayınları No:10, Ankara, 1994.

5. Sertkan, Y., "Halkla İlişkiler Açısından Çatışma Yönetimi”, A. Ü. Sosyal Bilimler Enstitüsü, Yayımlanmamış Yüksek Lisans Tezi, s.115, Ankara, 1997.

6. Hendrıcks, W., "How to Manage Conflict, National Press Publications, An Interdisciplinary Approach, Praeger Publishers", pp.5-16, New York, 1991.

7. Korkmaz, M., "Örgütlerde Çatışma ve Nedenleri”, Ankara,1994. 
8. Van Slyke, E.J. “Facilitating Productive Conflict”, HR Focus, Vol: 74. Is: 4, pp.17,1997.

9. Baron, R. A., " Behavior in Organizations, Allyn and Bacon”, Boston, 1986.

10. Bergman, T. J., VOLKEMA, R. J., "Understanding and Managing Interpersonel Conflict at Work: Its Issues, Interactive Processes and Consequences" Managing Conflict: An Interdisciplinary Approach, Praeger Publishers, pp. 5-16, New York, 1989.

11. Kindler, H. S., "Managing Conflict Constructively", Training and Development, Vol: 50, Iss.:7, pp.11-13,1996.

12. Morphy, J., " Managing Conflict at Work, Business One Irwin/Mirror Pres", New York, 1994.

13. Tjosvold, D., "The Conflict Pozitive Organization, Addison-Wesley Publishing", California, 1991.

14. Ross, M.H., " The Management of Conflict, Yale University Press", New Haven, 1993.

15. Tezer, E., "Conflict Behaviors and Their Relationship to Popularity", Adolescence, Winter 2001, Vol:36, Iss:144,s. 697, 2001.

16. Ural, A., "Illköğretim Okulu Yöneticilerinin Öğretmenlerle Aralarındaki Çatışmaları Yönetme Yöntemleri”, A.İB.Ü. Sosyal Bilimler Enstitüsü, Yayımlanmamış Doktora Tezi, Bolu, 1997.

17. Burke, R. J., "Methods of Resolving Sperrior-Subordinate Conflict The Constractive Use of Subordinate Differences and Disagreements", Organizational Behavior and Human Performance, Vol: 5, pp. 393-411, 1970.

18. Aydın, M. , "Örgütlerde Çatışma, Bas Yay Matbaası", s.35, Ankara, 1984.

19. Baksı, H., "Örgütlerde Çatışma ve Yönetimi”, H.Ü. Sosyal Bilimler Enstitüsü, Yayımlanmamış Yüksek Lisans Tezi, s. 104-108, Ankara, 1998.

20. Gümüşeli, A.İ., "İzmir Ortaöğretim Okulları Yöneticilerinin Öğretmenler İle Aralarındaki Çatışmaları Yönetme Biçimleri”, A.Ü. Sosyal Bilimler Enstitüsü, Yayımlanmamış Doktora Tezi, s.269, Ankara, 1994.

21. Ashworth, M.A., "A Study of Conflict Management Styles of Principals and Superintendents in the Public Schools of Ohio, Dissertation Abstracts International", Vol: 50, Iss.:8, pp.508, 1990.

22. Lawrence, P. R., LORSCH, J.W., "Differantation and Integration in Complex Organizations", Administrative Science Quarterly, Vol:12, pp.1-47, 1967.

23. Adams, D.C., "Perceptions of Conflict, Conflict Management Styles and Commitment in Middle Level Schools, Dissertation Abstracts International", Vol: 50, Iss.:7, pp.1854, 1990.

24. Wanasırı, W., "Interpersonal Conflict Handling Styles of Private Vocation School Principals in Thailand, Dissertation Abstracts International", Vol: 57, Iss.: 8, pp.2315, 1996. 